\title{
Development of Financial and Economic Instruments for the Formation and Management of Innovation Clusters in the Region
}

\author{
Mikhail Yakovlevich Veselovsky \\ State Institution of Higher Academic Education of Moscow Region, "Financial Technology Academy" \\ Russia, 141070, Moscow Region, Korolev, Gagarin Street, 42 \\ Tatiana Vitalievna Pogodina \\ Federal State-Funded Educational Institution of Higher Professional Education \\ "Financial University under the Government of the Russian Federation" \\ Russia, 125993, Moscow, Leningrad Prospect, 49 \\ Ibrahim Iragievich Idilov \\ Ramzan Yusupovich Askhabov \\ Madina Albekhadzhiyevna Abdulkadyrova \\ Federal Public Budgetary Educational Institution of Higher Education \\ "Grozny State Oil Technical University of a Name of the Academician M. D. Millionshchikov" \\ Russia, 364051, Chechen Republic, Grozny, Ordzhonikidze Square, 100
}

\section{Doi:10.5901/mjss.2015.v6n3p116}

\section{Abstract}

The article discusses the main directions of stimulating economic development of the region and one of its most important components - innovation. The need to expand the use of financial and economic instruments is justified, the analysis of the development of regional innovation clusters, means and directions of scientific and technological development of the country is conducted. The guidelines to improve the mechanisms to foster innovation, tools of implementation and evaluation of innovative clusters are given.

Keywords: innovation, innovation clusters, financial and economic instruments, innovative processes.

\section{Introduction}

Investment policy focused on strengthening the innovation potential of the regional economy is an important instrument to enhance its competitiveness, increase the quality and standard of living of the population. One of the mechanisms to improve the innovative potential of the region is the creation of innovation clusters.

Formation of regional clusters is made by means of financial and economic instruments that can help mobilize the objective prerequisites for effective investments in innovation and ensure the participation of sufficient financial resources to fund innovative projects.

If we consider certain aspects of the cluster, the assessment of its innovation potential can be carried out in the context of the following areas: assessment of innovation level; assessment of production activity; assessment of the development of small enterprises in the cluster; assessment of export opportunities of the cluster; evaluation of the financial capacity of the cluster (Pogodina T.V. and Medvedev T.A., 2013).

Interrelatedness of the researches focused on building complex financial and economic instruments to stimulate the development of innovative potential of regional social and economic systems based on the cluster approach will harmonize the existing methods and instruments of development with the most effective ones and those of high priority for stimulating the development of innovation clusters in the regions.

This work is aimed at validating the theoretical and methodological approaches to the study of the processes of creation of innovation clusters using financial and economic instruments and at developing practical recommendations on 
the content, forms and methods of management of innovative potential of the regional social and economic system on this basis.

The conducted research is aimed at building sustainable growth of innovative potential of social and economic systems of the North Caucasus Federal District of the Russian Federation, taking into account the multiplier effect on the development of the core innovation clusters in order to optimize the territorial organization and ensure sustainable dynamics of the main mesoeconomic indicators.

\section{Methodology}

When conducting the study on the identification of features of the development of the regional economy in the conditions of its transition to an innovative way of development, the authors used the methods of empirical knowledge. They served as a means of collecting scientific and empirical facts that were exposed to theoretical, economic and statistical analysis. Theoretical analysis involved the allocation and consideration of individual aspects, features and peculiarities of the use of financial and economic instruments of cluster development. Economic and statistical analysis included the study of innovation potential of the regions. The individual facts were analyzed, regrouped and systematized. The common patterns of innovative development of regional clusters were identified. The analysis is accompanied by synthesis that facilitated the penetration into the essence of innovation and their impact on the economy of the regions of the Russian Federation.

The study also contains inductive and deductive methods. These logical methods made it possible to generalize the theoretical empirical data on the impact of innovation on economic growth of the regions of Russia.

Theoretical methods were needed to identify the problems on improving mechanisms to encourage innovation, to formulate the main hypotheses of the study and to assess the evidence collected in the field. Theoretical methods have also been associated with the study of specialized literature (Drucker P., 1981).

The study of literature has given the opportunity to learn the most studied issues and identify problematic ones in the use of financial and economic instruments for the development of innovative clusters. Much attention has been paid to the issues that are under scientific debate, which is already well studied, and what problems have not been resolved yet.

\section{Results}

\subsection{Key approaches to improving the innovative capacity of the regional social and economic system}

Innovative potential of regional social and economic system is a unified interactive set of features and capabilities of business, government and society to accumulate, implement and develop its innovatization providing an adequate level of competitiveness. Innovatization of the regional social and economic system is a deliberately organized and managed process of search, selection, storage, implementation and development of its innovative capacity through innovation and innovative activities of business, government and society. Innovativeness of the regional social and economic system is the capacity and the ability of businesses to creative activities.

Innovative potential of each of the regional social and economic system can simultaneously be part of various innovative potential supersystems whose goals may be inconsistent. In this case, the only option to improve the innovative potential of supersystems at different levels is to identify the most innovative global goals formed on megaand macro levels (Lyasnikov N.V., Dudin M.N., Sekerin V.D., Veselovsky M.Y., Aleksakhina V.G., 2014).

Identification of factors affecting the current status and trends in the development of innovative potential of the region, in our view, should also be based on two principles: identification of causal and functional connections and setting their targets. These connections and goals can serve as a key factor in the development of innovative potential of spatial social and economic systems of any level (Sandu I.S., Atarov N.Z., 2014).

A key approach to improving the innovative capacity of the regions of Russia is the formation of innovation clusters. Let us analyze the effect of innovative technological factors on the ability of the central (CFD), Northwestern (NWFD), South (SFD), the North Caucasus (NCFD), Volga (VFD), Ural (UFD), Siberian (SFD) and the Far East (FEFD) federal districts of Russia to the creation of innovation clusters (Table 1) (the official website of the Federal State Statistics Service). 
Table 1. Analysis of the impact of innovative technologies and informational resources on the region's ability to create innovative regional clusters

\begin{tabular}{|c|c|c|c|c|c|}
\hline Indicators & Districts & 2000 & $\begin{array}{l}\text { Average for } \\
2005-2008\end{array}$ & $\begin{array}{l}\text { Average for } \\
2009-2012\end{array}$ & $\begin{array}{c}\text { Deviation of } \\
\text { 2012/2009 from } \\
\text { 2008/2005 }\end{array}$ \\
\hline \multirow{9}{*}{ Innovative activity of enterprises, \% } & RF & 8.8 & 9.8 & 9.9 & 0.1 \\
\hline & 1. CFD & 10.0 & 10.1 & 9.6 & -0.5 \\
\hline & 2. NWFD & 7.7 & 9.8 & 10.3 & 0.5 \\
\hline & 3. SFD & 8.1 & 8.7 & 7.2 & -1.5 \\
\hline & 4. NCFD & 6.2 & 6.6 & 5.9 & -0.7 \\
\hline & 5. VFD & 10.1 & 11.9 & 12.4 & 0.5 \\
\hline & 6. UFD & 10.6 & 11.3 & 11.0 & -0.3 \\
\hline & 7. SFD & 6.1 & 7.9 & 8.2 & 0.3 \\
\hline & 8. FEFD & 6.3 & 6.3 & 9.7 & 3.4 \\
\hline \multirow{9}{*}{$\begin{array}{l}\text { Share of innovative products, works, } \\
\text { services, } \%\end{array}$} & $\mathrm{RF}$ & 4.4 & 4.8 & 5.9 & 1.1 \\
\hline & CFD & 7.4 & 4.5 & 6.1 & 1.6 \\
\hline & NWFD & 5.7 & 3.7 & 4.9 & 1.2 \\
\hline & SFD & 2.4 & 4.3 & 4.8 & 0.5 \\
\hline & NCFD & 0.6 & 5.1 & 8.1 & 3.0 \\
\hline & VFD & 6.2 & 9.7 & 10.9 & 1.2 \\
\hline & UFD & 2.0 & 2.9 & 2.3 & -0.6 \\
\hline & SFD & 1.0 & 1.8 & 2.0 & 0.2 \\
\hline & FEFD & 0.9 & 1.5 & 11.5 & 10.0 \\
\hline \multirow{9}{*}{$\begin{array}{l}\text { Ratio of created and used advanced } \\
\text { manufacturing technologies, } \%\end{array}$} & RF & 0.98 & 0.45 & 0.53 & 0.08 \\
\hline & 1. CFD & 1.14 & 0.46 & 0.55 & 0.09 \\
\hline & 2. NWFD & 2.00 & 0.96 & 1.27 & 0.31 \\
\hline & 3. SFD & 0.42 & 0.41 & 0.40 & -0.01 \\
\hline & 4. NCFD & 0.27 & 0.42 & 0.40 & -0.02 \\
\hline & 5. VFD & 0.67 & 0.31 & 0.32 & 0.01 \\
\hline & 6. UFD & 1.43 & 0.49 & 0.37 & -0.12 \\
\hline & 7. SFD & 0.81 & 0.63 & 0.67 & 0.04 \\
\hline & 8. FEFD & 1.29 & 0.26 & 0.26 & 0.00 \\
\hline \multirow{9}{*}{$\begin{array}{l}\text { Proportion of enterprises using information } \\
\text { and communication technologies, } \%\end{array}$} & 1. CFD & 84.6 & 91.7 & 93.9 & 2.2 \\
\hline & 2. NWFD & 83.6 & 92.8 & 94.2 & 1.4 \\
\hline & 3. SFD & 89.5 & 92.7 & 95.2 & 2.5 \\
\hline & 4. NCFD & 84.5 & 90.6 & 91.7 & 11 \\
\hline & 5. VFD & 81.5 & 93.2 & 95.2 & 2.0 \\
\hline & 6. UFD & 81.5 & 91.4 & 94.9 & 3.5 \\
\hline & 7. SFD & 83.0 & 94.7 & 96.0 & 1.3 \\
\hline & 8. FEFD & 85.3 & 89.1 & 92.7 & 3.6 \\
\hline & 1. CFD & 85.1 & 91.0 & 92.6 & 1.6 \\
\hline
\end{tabular}

The leader by the force of the impact of the innovative technology factor in 2009-2012 was the Northwestern Federal District, followed by the Volga Federal District. A marked improvement in the provision and efficiency of innovation and technological factors occurred in the Far East and the North Caucasian Federal Districts. At the same time, a significant reduction in the innovative capacity was observed in the South and the Ural Federal Districts (Kopylova, 2011).

\subsection{Modern trends in the development of innovation clusters in the regions of Russia on the example of the North Caucasian Federal District}

Innovative processes based on the cluster approach have received differentiated development in the federal districts of Russia. One of the regions lagging far behind in this area is the North Caucasian Federal District. What are the causes of this gap and what methods and tools should be used to tackle this problem? Note that this issue is relevant not only for this district, but also for Russia as a whole, since the effective promotion of the national economy on an innovative way will be possible only due to the reduction in the level of differentiation of social and economic development of the 
territories (Davydov A.A., 2014, Mingaleva Z., Mirskikh I., 2014).

North Caucasian Federal District includes seven subjects of the Russian Federation - Republic of Dagestan, Republic of Ingushetia, Kabardino-Balkar Republic, Karachay-Cherkess Republic, Republic of North Ossetia-Alania, Stavropol Territory and Chechen Republic.

North Caucasian Federal District has a favorable geographical position and favorable conditions for the development of agriculture, tourism, health resort industry, electric power, mining and manufacturing sectors of the industry, as well as the developed transit functions. Despite these virtues, its absolute benefits still remain unfulfilled, because the district still does not have the investment attractiveness due to the unstable social, political and economic situation. The complex social, economic and political processes are intertwined with the complex ethnic and inter-ethnic problems in the region, which largely prevents the dynamic development of the district.

Some subjects of the North Caucasus Federal District are among the least economically developed regions of the Russian Federation due to the extremely insufficient level of development of the economic and social sphere. In particular, the district is characterized by high unemployment, complex crime situation and tense social situation. By such key social and economic indicators as gross regional product per capita, labor productivity, average wage, fiscal capacity, the level of development of the real sector of the economy and involvement in foreign economic activities, North Caucasian Federal District lags well behind other federal districts of Russia. The low level of investment attractiveness of the North Caucasus Federal District is combined with a high level of financial and investment risks.

At the same time, the district has a significant natural resource potential, which is currently a key factor for the successful development of innovative clusters. In addition, as it was revealed earlier, the importance of the impact of the factor of innovative technology increases in the North Caucasus Federal District, which enhances optimism about the future innovation development of the district.

North Caucasian Federal District has a unique combination of balneology resources - mineral drinking waters, thermal waters and therapeutic mud. About 30 percent of all Russian mineral water resources are concentrated there, which is comparable with the resources of the central regions of the European part of the Russian Federation. More than 70 percent of reserves of thermal waters of the Russian Federation are also located in this territory.

Production potential is primarily represented by the production of refined products, as well as food and chemical industry, mechanical engineering, metallurgy and production of construction materials.

Restoration of ore mining production and production of tungsten and molybdenum concentrates on Tyrnyauz tungsten and molybdenum plant is very important for the economy of the North Caucasus Federal District in connection with the projected increase in demand for rolled alloy steel - instrumental, bearings and stainless - by 2020 . The prospects for the production of precious metals should also be noted.

Depreciated fixed assets of industrial enterprises in the North Caucasus Federal District need to be renewed. This in particular applies to Chechen Republic, Republic of Dagestan and Republic of Ingushetia. Therefore, the real investment processes aimed at modernization and renewal of the material and technical base are particularly relevant for this district.

At the same time, the North Caucasian Federal District has a number of advantages - convenient geographical location in relation to the major markets, the availability of natural resources (oil, ores, building materials) and spare capacity (production sites, on the basis of which it is possible to increase production), a relatively developed transport network (rail and road) and the growing demand for industrial products, both in the regions of the Russian Federation and in countries near and far abroad (Sandu I.S., Ryzhenkova N.E., Veselovsky M.Y., Solovyov A.Y., 2014).

On the basis of available economic resources, potential demand and opportunities to create competitive products, there are following priority sectors of social and economic development, on the basis of which it is advisable to carry out the process of the creation of innovative clusters:

- production of building materials (cement, plaster, floor and wall materials, cellular concrete, bricks, concrete, sheet and foam glass, concrete products, products made of basalt, composite nanomaterials);

- consumer goods industry (wool processing, manufacture of textiles, clothing manufacture, footwear, leather goods, furs);

- chemical industry (nitrogen fertilizers, plastics, organic monomers, olefins, aromatics, pharmaceuticals);

- mechanical engineering (automobiles and automotive components, small tools and equipment, electrics and electronics, shipbuilding, medical equipment);

- metallurgy (refined metals and primary products, metal building constructions);

- extraction of minerals and ores (mining and production of concentrates of nonferrous metals, mining and production of copper and zinc metals, mining of mineral raw materials for construction); 
- fuel industry (extraction and processing of crude oil).

In the meantime, there are following priorities for the development and creation of clusters in some subjects:

- Republic of Dagestan - production of construction materials, food processing, mining of minerals and ores, fuel industry and consumer goods industry,

- Republic of Ingushetia - consumer goods and fuel industry, construction materials,

- Kabardino-Balkar Republic - consumer goods industry, mining of minerals and ores, metallurgy,

- Karachay-Cherkess Republic - consumer goods industry, mining of minerals and ores, construction materials and metallurgy,

- Republic of North Ossetia-Alania - manufacture of building materials, consumer goods industry, metallurgy, mining of minerals and ores, chemical industry,

- Chechen Republic - production of construction materials, fuel, food and consumer goods industry,

- Stavropol region - almost all sectors of industry, the most promising of which are chemical industry, machine building and construction materials.

Regional authorities pay great attention to the innovative development of their region. There are a significant number of legal and target documents regulating this area, including regional laws, development strategies and decrees (Dudin M.N., Lyasnikov N.V., Veselovsky M.Y., Sekerin V.D., Aleksakhina V.G. 2014).

In addition to the regional development support of these industries, the district participates in the state program "Development of the North Caucasus Federal District" for the period up to 2025". The above program is designed to promote an integrated social and economic development of the region, increase its investment attractiveness, stimulate the development of the priority areas of social and economic field, develop high-tech and knowledge-intensive industries, create and develop the industrial and innovation clusters, including the tourism sector (Dzhamaldinova M., Sidorov V., 2012).

At the same time, it should be noted that in addition to target mechanisms of creating innovative clusters in the North Caucasus Federal District, it is advisable to actively use and develop other financial and economic methods, including the tools of risk management, direct and indirect government support. The district has insufficiently developed infrastructure of innovation activity, lacks many development institutions and neglects innovative entrepreneurship.

The regional government is advisable to pay more attention to the formation of an effective system of education, training and retraining of personnel, which, on the one hand, can reduce social tensions in the region, and on the other hand, will ensure an inflow of highly qualified personnel to industrial and social facilities that are necessary to ensure transition of the economy to an innovative way of development (Pogodina T.V., Stanovova N.N., 2014).

\subsection{Investigation of financial and economic instruments used to stimulate the formation of innovation clusters in the region}

The development of innovative clusters necessitates the use of financial and economic instruments to stimulate these processes. Financial and economic instruments should be used at different levels, including, in particular, the federal and regional levels.

At the federal level, there is support for the processes of formation and development of innovative clusters. The most common financial and economic instruments to stimulate cluster formations are:

- provision of inter-budget subsidies;

- inclusion of cluster development activities to the federal target programs and state programs of the Russian Federation;

- tax exemptions on VAT and income tax, property tax, etc.;

- involvement of state development institutions.

To encourage the development of innovative clusters at the federal and regional levels, quite diverse economic and financial instruments are used. At the federal level, government development institutions are involved into the cluster development programs: GC "Vnesheconombank", OJSC "HMLA", Foundation for Assistance to Small Enterprises in Science and Technology, OJSC "Russian Venture Company", JSC "RUSNANO", Foundation for Assistance of the Centre of Development and Commercialization of New Technologies. Large companies with state shares, performing innovative development program, will be involved into activities of pilot clusters. Organizer and coordinator of the innovation process is the Ministry of Economic Development of Russia, tasked to form and to provide financial and economic support to create innovative regional clusters (Dudin M.N., Ljasnikov N.V., Pankov S.V., Sepiashvili E.N., 2013).

Regional authorities are interested in the development of not only the federal branches and production values, but 
also other sectors of the economy through the creation of innovation clusters of regional importance. In most regions, there are a significant number of documents regulating this area, including regional laws and development strategies, decrees and orders. In many regions of the district, the state provides support in the following forms: (Table 2).

Table 2 - Financial and economic instruments used at the regional level to foster the creation of innovative clusters

\begin{tabular}{|l|l|l|}
\hline No & Financial instruments & Economic instruments \\
\hline 1 & Provision of budget investments & $\begin{array}{l}\text { Provision of state guarantees of the federal subject for the } \\
\text { implementation of innovation project }\end{array}$ \\
\hline 2 & Provision of subsidies from the regional budget & $\begin{array}{l}\text { Provision of minimum rents to small and medium-sized businesses in the } \\
\text { use of objects of regional state property }\end{array}$ \\
\hline 3 & $\begin{array}{l}\text { Provision of investment tax loan, tax benefits in terms } \\
\text { of the amounts to be paid to the regional budget }\end{array}$ & $\begin{array}{l}\text { Provision of information and consulting support for the innovative } \\
\text { projects, help in the formation of project documentation }\end{array}$ \\
\hline
\end{tabular}

Thus, the financial and economic instruments of direct regulation and indirect stimulation of the development of innovative clusters are actively used at the federal and regional levels. We consider it appropriate to supplement the existing economic and financial instruments with methods of strategic planning, organizational and institutional nature (Troshin A.S., Kupriyanov S.V., Stryabkova E.A., Saldanha H.F.D., 2014).

\subsection{Priorities of development of financial and economic instruments to promote cluster development in the field of innovation}

The cluster approach has been widely used in developed and developing countries to encourage innovation processes. According to estimates of various experts, the total number of successful and stably functioning clusters in the world is more than 800 units, of which about 80 percent come from the developed countries. Leaders in the number and scope of activities of innovation clusters are the United Kingdom, the United States and Canada (Igonina L.L., 2014). In these countries, the task of establishing and strengthening regional innovation clusters was placed among the top national priorities. There are four forms of state support of innovation clusters in these countries:

- direct budget support of the development and introduction of new technologies and products;

- indirect support through tax policy and using administrative regulation;

- investments in the education system;

- support for infrastructure elements needed to promote innovative processes (Volkova N.N., Sakhno T.V., 2008).

Given the accumulated international experience (Menshikov M.A., 2012), these tools, in our view, can also be supplemented with the following:

- support of the infrastructure elements needed to promote innovation;

- creation of a system of subcontracting relationships between a range of the large companies and the network of small and medium ones;

- implementation of government programs to reduce risks and compensation of risk losses;

- development of innovative clusters around major research universities (Menshikov M.A., Levitsky A., 2013).

- increase of cooperation between the business and academic communities, including the field of information technology, biotechnology, pharmaceuticals and other sectors and industries.

Introduction of advanced production technologies, business and marketing innovation, commercialization of research and development are only possible if there is a developed innovation infrastructure that includes techno parks and policies, innovation and technology centers, business incubators, as well as other centers of collective use of scientific developments (Mingaleva Z. and Mirskikh I., 2014).

At the level of the Government of the Russian Federation, a key objective should be to coordinate the state and market regulation mechanisms to ensure implementation of these objectives. In connection with the task of economy transition to an innovative way of development, the state cannot ignore the regulation of innovative activity (Kenzhebayeva A., Turchekenova R., 2014). Therefore, the tools of direct state regulation should be combined with the tools of indirect financial and economic incentives (Afonasova M.A., 2010).

Similar activities should be carried out at the regional level. Only in this way the coherence of federal and regional authorities will be ensured. That will allow the best use of financial and economic instruments to promote the development of innovative clusters in the regional social and economic system. 


\section{Discussion}

The presented study about the identification of the specific use of financial and economic instruments to stimulate the creation and development of innovation clusters in the transition of the Russian economy to an innovative way of development is based on the methods of theoretical and empirical knowledge. As a result of the collection, generalization, systematization and analysis of economic, statistical and theoretical information about the impact of the financial and economic instruments on creation of innovative clusters and economic development of regions, we were able to confirm the hypothesis of the need to improve the financial and economic instruments to stimulate these processes. High reliability of the results is based on the writings of scientists Afonasova M.A., Drucker P., Dzhamaldinova M.D., Menshikov M.A., Sandu I.S. and others. The distinctive feature of this study is the account of the specifics of the Russian regions, as well as financial and economic instruments used to stimulate the development of scientific and technical area. Individual aspects, features, sides of this regulation were isolated and examined during theoretical analysis. The role and impact of the financial and economic instruments on increase in the number and quality of innovative products and services to the civil area were determined. The paper describes the main factors that hinder the development of science and scientific progress. The conclusions are provided about the internal and external threats to regional markets, in the absence of mechanisms of stabilization of innovation policy. Reliability of the results is confirmed by official statistical institutions in the country, located on the website of the State Statistics Committee.

\section{Conclusion}

Thus, over time and the development of economic science and economic practices, the approaches and methods to study the dynamics of innovative regional economy have undergone significant changes. They were affected by the development of scientific concepts in general and the accumulation of extensive statistical material that allowed to identify some general principles and laws of development of innovative potential of regions and social and economic processes that occur or origin there.

1. The key area to improve the social and economic development of regions is the creation of innovation clusters using financial and economic instruments.

2. The key financial and economic instruments to stimulate the development of clusters at the federal level are: provision of inter-budgetary subsidies; inclusion of cluster development activities to the federal programs and state programs of the Russian Federation; tax exemptions on VAT and income tax, property tax, etc.; involvement of state development institutions.

3. The most common instruments to stimulate the creation of innovation clusters at the regional level include: provision of budget investments; provision of subsidies from the regional budget; provision of minimum rents to small and medium-sized businesses in the use of objects of regional state property; provision of information and consulting support for innovative projects, help in the formation of project documentation, etc.

4. To encourage the further development of innovation clusters in the regions of Russia, it is advisable to use the financial and economic instruments including support for infrastructure elements needed to promote innovation; creation of a system of subcontracting relationships between a number of large companies and a network of small and medium ones; implementation of government programs to reduce risks and compensation of risk losses; development of innovation clusters around major research universities; increase in cooperation between the business and academic communities, including the field of information technology, biotechnology, pharmaceuticals and other sectors and industries.

\section{References}

Drucker, P. (1981). Toward the Next Economics and Other Essays. Harvard Business School.

Dudin, M.N., Lyasnikov, N.V., Veselovsky, M.Y., Sekerin, V.D., \& Aleksakhina, V.G. (2014). The problem of forecasting and modelling of the innovative development. Life Science Journal, 11(8s), 549-552.

Dudin, M.N., Ljasnikov, N.V., Pankov, S.V., \& Sepiashvili, E.N. (2013). Innovative Foresight as the Method for Management of Strategic Sustainable Development of the Business Structures. World Applied Sciences Journal, 26(8), 1086-1089.

Igonina, L.L. (2014). Financial mechanism of the venture capital investment: an analysis of the effectiveness in the Russian economy. Life Science Journal, 11(12), 215-220.

Kenzhebayeva, A., \& Turchekenova, R. (2014). State support for innovation policy: timeline. Life Science Journal, 11(9s), 251-256.

Lyasnikov, N.V., Dudin, M.N., Sekerin, V.D., Veselovsky, M.Y., \& Aleksakhina, V.G. (2014). The national innovation system: the conditions of its making and factors in its development. Life Science Journal, 11(6s), 535-538. 
Mingaleva, Z., \& Mirskikh, I. (2014). The main institutional instruments of intellectual property protection. Life Science Journal, 11(12s), 170-173.

Sandu, I.S., Ryzhenkova, N.E., Veselovsky, M.Y., \& Solovyov, A.Y. (2014). Economic aspects of innovation-oriented market economy formation. Life Science Journal, 11(12s), 242-244.

Sandu, I.S., \& Atarov, N.Z. (2014). Economic Aspects of assessing the effectiveness of foreign trade activity of industry. World Applied Sciences Journal, Vol. 29, 4, 581-584.

Troshin, A.S., Kupriyanov, S.V., Stryabkova, E.A., \& Saldanha, H.F.D. (2014). Role and place of economic mechanism in modern conditions. Life Science Journal, Vol. 11, 10s, 487-490.

Afonasova, M.A. (2010). The evolution of power systems. Institutional aspects of the strategy of innovative development of the Russian economy. Creative Economy, 1, 10-14.

Volkova, N.N., \& Sakhno, T.V. (2008). Russian industrial clusters. Poltava (pp. 532). Publishing house "Techservice".

Davydov, A.A. (2014). Innovation potential of Russia: present and future. Institute of Sociology, Russian Academy of Sciences. Retrieved 26.10.2014, from http://www.isras.ru/blog_modern_3.html/ 2014

Dzhamaldinova, M., \& Sidorov, V. (2012). Sustainable development of the enterprise as a result of the formation of innovative potential through the use of technological capabilities. Financial life, 3, 80-82.

Kopylova, K.V. (2011). Theoretical aspects of innovative entrepreneurship. Issues of Regional Economy, 4, 54-59.

Menshikova, M.A., \& Levitsky, A.V. (2013). Improving the management control function in the innovation economy (pp. 54-60). In the Proceedings of the Open scientific-practical conference of teachers of the Department of Economics: Strategies for Innovative Development of Enterprise.

Menshikova, M.A. (2012). Innovative methods of cost management in the industry. Issues of Regional Economy, 2, 114-119.

Official website of the Federal State Statistics Service. Retrieved 01.10.2014, from http://www.gks.ru/wps/wcm/connect/

Pogodina, T.V., \& Medvedeva, T.A. (2013). Innovative potential of social and economic system of the region. Economy. Taxes. Law, 6, 56-62.

Pogodina, T.V., \& Stanovova, N.N. (2014). The concept and elements of the innovation process. Scientific Review, 3, 266-269. 